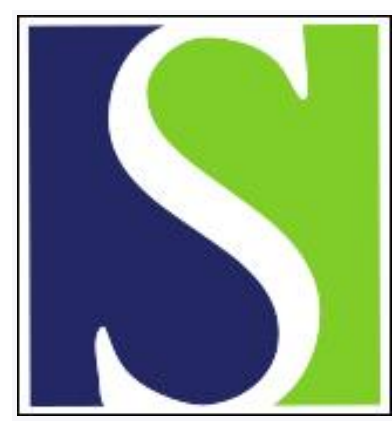

Scand J Work Environ Health 2000;26(6):482-491

https://doi.org/10.5271/sjweh.572

Issue date: Dec 2000

Acute myeloid leukemia and clonal chromosome aberrations in relation to past exposure to organic solvents

by Albin M, Björk J, Welinder $\mathrm{H}$, Tinnerberg $\mathrm{H}$, Mauritzson $\mathrm{N}$, Johansson B, Billström R, Strömberg U, Mikoczy Z, Ahlgren T, Nilsson P-G, Mitelman F, Hagmar L

Key terms: age; benzene; case-referent study; cytogenetic; effect modification; erythroleukemia; occupational limit value; population attributable risk; trisomy 8

This article in PubMed: www.ncbi.nlm.nih.gov/pubmed/11201395

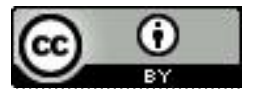




\title{
Acute myeloid leukemia and clonal chromosome aberrations in relation to past exposure to organic solvents
}

\author{
by Maria Albin, MD, ${ }^{1}$ Jonas Björk, BSc, ${ }^{1}$ Hans Welinder, PhD, ${ }^{1}$ Håkan Tinnerberg, PhD, ${ }^{1}$ Nils Mauritzson \\ MD, ${ }^{2}$ Bertil Johansson, MD, ${ }^{3}$ Rolf Billström, MD, ${ }^{2}$ Ulf Strömberg, PhD, ${ }^{1}$ Zoli Mikoczy, MSc, ${ }^{1}$ Tomas \\ Ahlgren, MD, ${ }^{4}$ Per-Gunnar Nilsson, MD, ${ }^{2}$ Felix Mitelman, MD, ${ }^{3}$ Lars Hagmar, MD'
}

\begin{abstract}
Albin M, Björk J, Welinder H, Tinnerberg H, Mauritzson N, Johansson B, Billström R, Strömberg U, Mikoczy Z, Ahlgren T, Nilsson P-G, Mitelman F, Hagmar L. Acute myeloid leukemia and clonal chromosome aberrations in relation to past exposure to organic solvents. Scand J Work Environ Health 2000;26(6):482-491.

Objectives The effects of occupational and leisure-time exposures on the risk of acute myeloid leukemia (AML) were investigated with emphasis on clonal chromosome aberrations $(\mathrm{CCA})$ and morphological subtypes.

Methods Consecutively diagnosed cases of AML ( $N=333)$ and 1 population referent per case were retrospectively included in the study. Information on worktasks, companies, and leisure-time activities was obtained with telephone interviews. Exposure probability and intensity were assessed by occupational hygienists. Associations were evaluated with logistic regression.

Results Exposure to organic solvents was associated with an increased risk of AML [low exposure: OR 1.5 (95\% confidence interval (95\% CI) $1.0-2.3$, moderate-high exposure: OR $2.3(95 \%$ CI 1.0-5.0)]. For exposure to solvents, but not to benzene, the OR was 1.2 (95\% CI 0.69-2.0) for "low" and 2.7 (95\% CI 1.0-7.3) for "moderate-high" exposure. The observed effects increased with intensity and duration of exposure. The estimated effects were higher for patients $>60$ years of age at the time of diagnosis. The effect of exposure to organic solvents was not differential with regard to morphology [except possibly erythroleukemia: OR 4.2, 95\% CI 1.0-17 or the presence of CCA in general]. No increased risk for AML with complex CCA or with total or partial losses of chromosomes 5 or 7 were observed, but a higher risk was found for AML with trisomy 8 (OR 11, 95\% CI 2.7_-42) as the sole aberration.
\end{abstract}

Conclusions Exposure to organic solvents was associated with an increased risk of AML. This association was not due to benzene exposure alone and may be modified by age. Furthermore, specific associations with trisomy 8 , and possibly also erythroleukemia, were suggested.

Key terms age, benzene, case-referent, cytogenetic, effect modification, erythroleukemia, occupational limit values, population attributable risk, trisomy 8 .

Acute myeloid leukemia (AML) is characterized by acquired, nonrandom clonal chromosome abnormalities, which have proved to be clinically and biologically important since they provide diagnostic, prognostic, etiologic, and pathogenetic information $(1,2)$. Some experimental studies indicate that different exposures may cause different types of clonal chromosome abnormalities (3-5). Furthermore, AML following radio- or chemotherapy differs cytogenetically from de novo AML $(6$, 7). The patterns for clonal chromosome abnormalities in treatment-related AML seem to vary with respect to the type of cytostatic drugs used. For example, alkylating agents have been associated with total or partial losses of chromosomes 5 and 7 and deletions of the short arms of chromosomes 3 and 12, whereas topoisomerase-II inhibitors have been linked to structural rearrangements of chromosome bands $11 q 23$ and $21 q 22(8,9)$. In addition, in peripheral lymphocytes of healthy workers exposed to high concentrations of benzene, dose-dependent gains (mainly trisomy) of chromosome 8 (10) and deletions of chromosomes 5 and 7 (11) have been found.

Known risk factors for AML include radio- and chemotherapy, benzene exposure, and smoking (12). In addition, exposure to other organic solvents (13), ex-

\footnotetext{
Department of Occupational and Environmental Medicine, Lund University Hospital, Lund, Sweden. Department of Internal Medicine, Division of Hematology, Lund University Hospital, Lund, Sweden. Department of Clinical Genetics, Lund University Hospital, Lund, Sweden.

Division of Hematology, Malmö University Hospital, Malmö, Sweden.
}

Reprint requests to: Dr Maria Albin, Department of Occupational and Environmental Medicine, Lund University Hospital, SE22185 Lund, Sweden. [E-mail: maria.albin@ymed.lu.se] 
tremely low frequency electromagnetic fields (ELMF) (14-18), hair dyes (19-21), pesticides (22), petroleum products and exhaust gases (23), animalborne viruses (24), and forestry work (25) have been indicated as risk factors, albeit with conflicting results $(12,26)$.

Studies of suggested occupational risk factors for specific subtypes of AML, as defined by morphology or karyotype, have not been consistent. Exposure was not associated with any specific morphology in one study (27), whereas others have indicated increased risks for acute myelomonocytic leukemia after benzene (28) and pesticide (29) exposures, increased risk for acute promyelocytic leukemia in electricians (30), and a possible association between exposure to solvents, insecticides, or petroleum products and erythroleukemia (31). With regard to clonal chromosome abnormalities, in some studies, AML patients exposed to solvents or pesticides (3133 ) or "chemicals" $(27,34)$ had a higher proportion of clonal chromosome abnormalities (especially complete or partial loss of chromosome 5 or 7 , and trisomy 8 ), but not in others $(16,35,36)$. It has also been suggested that AML in association with previous toxic occupational exposures has a worse prognosis and represents a distinct clinical, as well as cytogenetic, entity (32).

Little is known about the effect modification of exposure by age, gender, and smoking in AML. However, Sandler et al (37) observed an exposure-response between smoking and risk for AML only for subjects above the age of 60 years at the time of diagnosis.

The present study was undertaken to explore prevalent exposures, such as organic solvents, ELMF, and hair dyes, suggested as risk factors in previous studies with regard to overall risk for AML. Moreover, other objec- tives were to study characteristic clonal chromosome $a b-$ normalities as markers of exposure, differential risks for morphological subtypes, and effect modification by age, gender, and smoking.

\section{Subjects and methods}

\section{Cases}

Our study is based on a series of 372 consecutive cases of AML, diagnosed between 1976 and 1993; the subjects were at least 20 years of age when cytogenetically investigated at the Department of Clinical Genetics, Lund, which performs all cytogenetic analyses in southern Sweden. All referrals for such analyses are made within the public health system. The hematology departments at the Lund University Hospital and at the nearby hospital in Helsingborg, throughout the study period, included cytogenetic analyses as a routine in the diagnostic evaluation of hematological malignancies, indicating that the coverage of incident cases is most complete for these catchment areas (Lund-Helsingborg). Interview information was obtained for 333 cases (90\%) (table 1). The nonparticipating cases were older (median age 68 years) and more often women $(59 \%)$.

The medical records for each case were reviewed by 1 of 3 hematologists (38). The diagnoses were based on the morphological and clinical findings present at the time of the cytogenetic investigation. The morphological subtypes according to the French-American-British (FAB) classification were as follows: minimally differentiated (M0) 1 case, myeloblastic without maturation

Table 1. Descriptive data for the cases of acute myeloid leukemia investigated cytogenetically between 1976 and 1993 in Lund, Sweden, and for their population referents. (CCA = clonal chromosome aberrations)

\begin{tabular}{|c|c|c|c|c|c|c|c|c|c|c|c|c|c|c|c|}
\hline & \multirow{2}{*}{$\begin{array}{l}\text { Inter- } \\
\text { viewed } \\
\text { subjects } \\
\text { (N) }\end{array}$} & \multicolumn{3}{|c|}{ Year of diagnosis } & \multicolumn{3}{|c|}{ Year of birth } & \multicolumn{3}{|c|}{ Age (years) at diagnosis } & \multirow{2}{*}{$\begin{array}{l}\text { Men } \\
(\%)\end{array}$} & \multirow{2}{*}{$\begin{array}{l}\text { Inter- } \\
\text { view } \\
\text { with } \\
\text { next- } \\
\text { of-kin }\end{array}$} & \multirow{2}{*}{$\begin{array}{l}\text { Smok- } \\
\mathrm{ers}^{\mathrm{a}} \\
(\%)\end{array}$} & \multicolumn{2}{|c|}{$\begin{array}{l}\text { Chemo- } \\
\text { or radio- } \\
\text { therapyb }\end{array}$} \\
\hline & & Median & $\begin{array}{l}\text { toth } \\
\text { per- } \\
\text { cent- } \\
\text { ille }\end{array}$ & $\begin{array}{l}\text { 90th } \\
\text { per- } \\
\text { cent- } \\
\text { ile }\end{array}$ & Median & $\begin{array}{l}10 \text { th } \\
\text { per- } \\
\text { cent- } \\
\text { ile }\end{array}$ & $\begin{array}{l}\text { 9oth } \\
\text { per- } \\
\text { cent- } \\
\text { ile }\end{array}$ & Median & $\begin{array}{l}10 \text { th } \\
\text { per- } \\
\text { cent- } \\
\text { ile }\end{array}$ & $\begin{array}{l}\text { 90th } \\
\text { per- } \\
\text { cent- } \\
\text { ile }\end{array}$ & & & & $\begin{array}{c}\text { Inter- } \\
\text { view } \\
(\%)\end{array}$ & $\begin{array}{l}\text { Inter- } \\
\text { view } \\
\text { and } \\
\text { medical } \\
\text { records } \\
(\%)\end{array}$ \\
\hline \multicolumn{16}{|l|}{ Cases' } \\
\hline CCA & 169 & 1987 & 1979 & 1992 & 1926 & 1910 & 1951 & 62 & 32 & 76 & 42.6 & 88.8 & 46.2 & 6.5 & 17.8 \\
\hline Normal & 164 & 1988 & 1983 & 1993 & 1925 & 1913 & 1950 & 63 & 39 & 75 & 56.1 & 84.1 & 47.6 & 4.9 & 7.3 \\
\hline Referents ${ }^{c}$ & 351 & & & & 1925 & 1912 & 1952 & & & & 50.1 & 14.2 & 41.0 & 4.3 & \\
\hline
\end{tabular}

a Ever-smoker during the 20 years before the diagnosis of the case. Three cases and 3 referants with unknown smoking habits.

${ }^{t}$ Chemo- or radiotherapy (including treatment with isotopes) during the 20 years before the diagnosis of the case ( 14 cases, 14 referents), or at an unknown time ( 5 cases, 1 referent).

- The median number of jobs reported, irrespective of the information source, was 3.0 (10th percentile: $1.0,90$ th percentile: 5.0 ) for the cases and 3.0 (10th percentile: 1.0, 90th percentile: 6.0 ) for the referents. 
(M1) 64 cases, myeloblastic with maturation (M2) 101 cases, promyelocytic (M3) 19 cases, myelomonocytic (M4) 60 cases, monoblastic (M5) 26 cases, erythroleukemia (M6) 13 cases, megakaryoblastic (M7) 3 cases, and 46 cases that could not be classified (39-42).

\section{Cytogenetic investigations}

All the cytogenetic investigations were performed in a standardized fashion on bone marrow or peripheral blood samples that were taken before the start of the AML treatment. In short, the cells were adjusted to a concentration of $10 \% \mathrm{ml}$ and cultured for 24 and 48 hours in McCoy's 5 A medium supplemented with $20 \%$ fetal calf serum, Lglutamine, and antibiotics, and the chromosomes were banded by trypsin-Giemsa. Throughout the study period, the definition and description of clonal abnormalities followed the recommendations of the International System for Human Cytogenetic Nomenclature (43). In general, 25 metaphases were analyzed. The cytogenetic investigation was considered a failure if fewer than 10 metaphases could be investigated, and such cases are not included in this study. The analyses were blind with regard to exposure.

The cases were cytogenetically divided into normal or abnormal, with the latter further subgrouped on the basis of number of abnormalities [1,2, or complex (ie, $\geq 3$ aberrations)], prognostic category, and characteristic abnormality. The prognostic categories were bad [complex (if including total or partial chromosome 5 or 7 losses), $-5,5 q-,-7, \operatorname{der}(1 ; 7), t / \operatorname{inv}(3)(q 21 q 26)$, and $\mathrm{t}(9 ; 22)(\mathrm{q} 34 ; \mathrm{q} 11)], \operatorname{good}[\mathrm{t}(8 ; 21)(\mathrm{q} 22 ; \mathrm{q} 22)$, $\mathrm{t}(15 ; 17)(\mathrm{q} 22 ; \mathrm{q} 12-21)$, and $\operatorname{inv}(16)(\mathrm{p} 13 \mathrm{q} 22)]$, and intermediate [all other aberrations]. The following characteristic abnormalities were also considered: $-3 / 3 p-,-5 / 5 q-$, $-7 / 7 \mathrm{q}-,+8$ as a single anomaly, $\operatorname{der}(11)(\mathrm{q} 23)$, and $-12 /$ $12 \mathrm{p}$.

\section{Referents}

Statistics Sweden selected 3 referents for each case, matched with respect to gender, year of birth, and county of living from the study population (southern Sweden) within the calendar year in which each case was diagnosed. One referent in each matched set was randomly selected to be interviewed. When referents or their nextof kin could not be interviewed, other referents from the matched set were selected. Altogether 351 referents were included in the study (participation rate $72 \%$ ) (table 1 ). The nonparticipating referents were older (median age 68 years) and more often women $(60 \%)$.

\section{Information on exposure}

The subjects were retrospectively enrolled in the study and contacted with a letter describing the purpose of the study and the main questions to be addressed during the interview. A life-long occupational history was thereafter obtained during the period $1995-1997$ in a structured telephone interview made by 1 of 3 occupational health nurses who were aware of the case-referent status. The history included all jobs held for at least 1 year, including worktask, department, and name of company. No specific exposures were asked for in the interview, but follow-up questions were triggered concerning the application of pesticides in work as a gardener or horticulturist, lumberjack, railway worker (track maintenance), farmer, or farmhand; type of cargo in work as a driver or on a merchant ship; handling of cytostatics in work as a nurse; and working at a meat counter in work as a shop keeper or shop assistant. Information on extra jobs held for at least 1 year was collected in the same way as for the regular job.

The following hobby activities were explicitly inquired about: motor repair, artistic painting with oil, furniture renovation, construction of models, riding, animal breeding, hunting, and gardening. Follow-up questions were asked about activity period and average hours per week spent in the activity. A follow-up question on regular pesticide use was triggered by gardening as a hobby. Furthermore, questions were asked about regular hair dye use, and smoking habits. The medical history preceding the time of the case diagnosis included questions about radiotherapy, chemotherapy, and treatment with isotopes.

If the subject was deceased or too ill to participate, a next-of-kin was selected in the following order: spouse, parent, sibling, and child. Information had to be obtained from the next-of-kin more often for cases than for referents (table 1). The proportion of next-of-kin interviews increased as the age of the subjects increased (eg, nextof kin interviews were used for $93.3 \%$ of the cases and $23.5 \%$ of the referents older than 60 years of age). Spouses and children were the most frequently interviewed among the next-of-kin of both the cases ( $48 \%$ and $36 \%$, respectively) and the referents $(27 \%$ and $63 \%$, respectively).

\section{Exposure assessment}

Exposure assessment was performed by 1 of 3 occupational hygienists, on the basis of the structured telephone interviews made by the occupational health nurses. The occupational hygienists were unaware of the case-referent status. The assessments for all cases, and for the corresponding referents, were restricted to exposure periods of at least 1 year during the 20 years before the diagnosis of the case. All codings were supervised by double-checks performed by one of the hygienists (HW). 
Exposure assessments were performed for established, and suggested, occupational and leisure-time risk factors for AML (listed in table 2). Quantitative definitions of the different exposure intensity categories were used for organic solvents, benzene, and ELMF. "Low", "moderate", and "high" exposure to organic solvents corresponded to $1-5 \%, 5-15 \%$, and $>15 \%$, of the present Swedish occupational exposure limits, respectively. For benzene, the cotresponding categories were $0.05-0.2$, $0.2-0.5$, and $>0.5 \mathrm{mg} / \mathrm{m}^{3}$. Exposure to ELMF was classified according to 8-hour arithmetic averages reported for different occupations (44), with the following categories: $0.23-0.30,0.30-0.50$, and $>0.50 \mu \mathrm{T}$. For all other occupational exposures, the different exposure intensity categories were delineated by examples of occupations or tasks. For exposure to aromatic organic solvents (excluding benzene), chlorinated organic solvents, and cytostatic drugs, only dichotomous assessment (exposed/unexposed) was possible. Exposure to cattle, poultry and fresh meat was considered together due to the hypothesis of a common causal factor (animalborne viruses). The main occupation in this exposure category was farmer.

For regular hair dye use and smoking, classification was directly based on the specific questions in the interview. Cases and referents were classified as smokers if they had smoked for at least 1 year during the 20 years before the diagnosis of the case. Leisure-time exposures were assessed for all the agents, except ELMF, ionizing radiation and chemotherapeutic drugs.

For the occupational exposures, the confidence in the exposure codings was assessed (high confidence or not) on the basis of the quality of information on worktasks and exposures in the interview data and the confidence of possible exposure for different worktasks.

Interrater reliability was assessed after the exposure assessments were finalized for all the interview forms. The main occupational hygienist (HW) reassessed 198 randomly selected interview forms, unaware of the original exposure assessments. In the original assessment 47 of these subjects were classified as having certain occupational or leisure-time exposure to organic solvents, $70 \%$ of them were classified in the same way in the reassessment. The 198 interviews were also reassessed by a 2 nd occupational hygienist. The concordance between the 2 reassessments was slightly better $(80 \%)$ than between the new and old assessments; this difference indicated a slight shift in assessment with time. However, there were no differences in the concordance between the cases and referents. Only the old assessments were used in the analyses of exposure effects.

We chose to include information on previous chemoor radiotherapy from both the interview and the medical records (cases only) in the classification, since the interview was insensitive in detecting such treatment, as judged from comparisons with the medical records available for the cases (table 1). Thus the effect estimates were likely to be biased and therefore have not been presented.

\section{Statistical analyses}

When only general matching factors such as age and gender are used, confounding can normally be more efficiently controlled in a stratified analysis than in a matched analysis (45). In our study, all effect estimates were therefore obtained by unconditional logistic regression (46), stratified for age into 3 broad categories ( $\leq 54$, $55-69$, and $\geq 70$ years) and gender. Comparison with estimates from a conditional logistic regression model (46) showed that the stratification sufficiently accounted for the effect of the matching variables. Year of diagnosis and county of residence did not influence the effect estimates and were therefore not included. When the trends were tested, the coefficient from a logistic model with the exposure intensity ( $1=$ hobby-low, $2=$ moderate, $3=$ high) and duration (as a continuous variable), respectively, was used as the test statistic, provided that the data were fairly consistent with such a model (47). The population attributable risk, with $95 \%$ confidence intervals obtained with the Mantel-Haenszel approach, was estimated when appropriate $(48,49)$.

In order to reduce exposure misclassification, only exposure assessments with high confidence for occupational exposures were used in the analyses. Subjects were classified as unexposed for a particular agent only if they were unexposed with high confidence during the entire assessment period. Subjects were classified as exposed if they were exposed with high confidence for at least 1 year during the assessment period. Subjects that could not be classified as exposed or unexposed with high confidence were excluded from the analyses. A less restrictive approach did not change the results substantially, and they therefore have not been presented. However, the approach implies that the presented exposure durations and intensities are minimum values.

\section{Resulis}

\section{All acute myeloid leukemias}

Exposure to all organic solvents was associated with a moderately increased overall risk for AML (table 2). Restriction of the analysis to the subjects interviewed in person (45 cases, 301 referents) gave a similar, but less precise estimate [OR $1.4,95 \%$ confidence interval $(95 \%$ CI) $0.65-3.1]$. Adjustment for smoking and treatment with radio- or chemotherapy changed the estimate marginally (OR 1.7, 95\% CI 1.1-2.5). A stratified analysis 
Table 2. Effects of occupational and hobby exposure $\leq 20$ years before the diagnosis on the risk for acute myeloid leukemia. Only cases and referents with exposure assessment with high confidence were included in the analyses [ELMF= extremely low-frequency magnetic fields (occupational exposure only), $\mathrm{OR}=$ odds ratio, $95 \% \mathrm{Cl}=95 \%$ condifence interval]

\begin{tabular}{|c|c|c|c|c|c|c|c|c|}
\hline \multirow[t]{2}{*}{ Exposurea } & \multicolumn{3}{|l|}{ Cases (N) } & \multicolumn{3}{|c|}{ Referents (N) } & \multirow[t]{2}{*}{$O R^{b}$} & \multirow[t]{2}{*}{$95 \% \mathrm{Cl}$} \\
\hline & Exposed & Unexposed & Uncertain & Exposed & Unexpo & certain & & \\
\hline \multicolumn{9}{|l|}{ Organic solvents } \\
\hline All & 88 & 205 & 40 & 67 & 243 & 41 & 1.6 & $1.1-2.4$ \\
\hline Hobby-low levels & 70 & & & 57 & & & 1.5 & $1.0-2.3$ \\
\hline Moderate-high levels & 18 & & & 10 & & & 2.3 & $1.0-5.0$ \\
\hline Benzene & 39 & 278 & 16 & 29 & 302 & 20 & 1.5 & $0.89-2.6$ \\
\hline Hobby-low levels & 28 & & & 19 & & & 1.6 & $0.89-3.1$ \\
\hline Moderate-high levels & 11 & & & 10 & & & 1.3 & $0.52-3.1$ \\
\hline Chlorinated solvents ${ }^{c}$ & 12 & 293 & 28 & 16 & 309 & 26 & 0.78 & $0.36-1.7$ \\
\hline Gasoline and diesel fuel & 56 & 270 & 7 & 48 & 289 & 14 & 1.3 & $0.83-2.0$ \\
\hline Hobby-low levels & 45 & & & 37 & & & 1.3 & $0.82-2.2$ \\
\hline Moderate-high levels & 11 & & & 11 & & & 1.1 & $0.48-2.7$ \\
\hline Gasoline or diesel exhaust & 57 & 260 & 16 & 51 & 278 & 22 & 1.2 & $0.79-1.9$ \\
\hline Hobby-low levels & 44 & & & 41 & & & 1.2 & $0.73-1.9$ \\
\hline Moderate-high levels & 13 & & & 10 & & & 1.5 & $0.62-3.5$ \\
\hline Pesticides & 38 & 284 & 11 & 47 & 287 & 17 & 0.83 & $0.52-1.3$ \\
\hline Hobby-low levels & 28 & & & 39 & & & 0.73 & $0.44-1.2$ \\
\hline Moderate-high levels & 10 & & & 8 & & & 1.3 & $0.50-3.4$ \\
\hline Fresh meat or cattle or poultry & 60 & 272 & 1 & 55 & 290 & 6 & 1.2 & $0.78-1.7$ \\
\hline Hobby-low levels & 23 & & & 18 & & & 1.4 & $0.73-2.6$ \\
\hline Moderate-high levels & 37 & & & 37 & & & 1.1 & $0.65-1.7$ \\
\hline Fresh wood & 26 & 300 & 7 & 31 & 311 & 9 & 0.87 & $0.50-1.5$ \\
\hline Low levels & 21 & & & 24 & & & 0.91 & $0.49-1.7$ \\
\hline Moderate-high levels & 5 & & & 7 & & & 0.73 & $0.23-2.4$ \\
\hline ELMF & 63 & 237 & 33 & 67 & 252 & 32 & 1.0 & $0.66-1.5$ \\
\hline Low levels & 28 & & & 31 & & & 0.96 & $0.56-1.7$ \\
\hline Moderate & 25 & & & 23 & & & 1.1 & $0.62-2.1$ \\
\hline High levels & 10 & & & 13 & & & 0.82 & $0.35-1.9$ \\
\hline Regular use of hair dyes & 65 & 268 & - & 69 & 282 & - & 0.98 & $0.64-1.5$ \\
\hline
\end{tabular}

a Occupational exposure to ionizing radiation and cytostatics was too rare to permit analyses. In addition, the analysis for all aromatic solvents is not presented due to a close association with exposure to all organic solvents.

OR obtained from unconditional logistic regression analyses. (See the text.)

Only 1 level of assessment.

indicated an increasing risk with increasing intensity of exposure [table 3, test for trend (hobby-low, moderate, high), $\mathrm{P}<0.01]$. Typical occupations in the moderate-high intensity category were painters and rubber industry workers, and in the low-intensity category carpenters and motor mechanics prevailed.

Suggested associations were observed for exposure to benzene, but not for chlorinated hydrocarbons. No increasing risk by intensity of benzene exposure was observed. Effects from exposure to all organic solvents and to benzene were separated by restriction of the analyses to subjects exposed to solvents other than benzene. The odds ratio was 1.2 (95\% CI $0.69-2.0)$ for the hobbylow category and 2.7 (95\% CI 1.0-7.3) for the moderate-high category; this result indicates that the observed effect was not due to benzene exposure alone. Separation of the effects from exposure to all organic solvents from that of aromatic solvents other than benzene was not possible because they were too closely associated.

Analyses by duration of only occupational exposure (ie, excluding leisure-time exposures) to all organic solvents also indicated a positive association with risk for AML [ $1-7$ years ( 12 cases, 15 referents): OR $0.98,95 \%$ CI $0.44-2.2 ; 8-14$ years ( 15 cases, 15 referents): OR $1.2,95 \%$ CI $0.56-2.5 ; \geq 15$ years (30 cases, 17 refer- ents): OR $2.1,95 \%$ CI $1.1-4.1 ; \mathrm{P}=0.03]$. A similar higher risk for longer durations of leisure-time exposure was observed, but with wider confidence intervals. Restricting the duration analysis to occupational benzene exposure resulted in wide and thus noninformative confidence intervals. No clear association between duration of exposure and risk was observed for any of the other agents.

The population attributable risk from occupational and leisure-time exposure to all organic solvents was $11 \%$ (95\% CI 2.6-20\%), OR 1.6, 30\% exposed cases (table 2), the main proportion being attributable to leisure time and low occupational exposure due to the high prevalence. A similar estimate [14\% (95\% CI $2.5-26 \%)$, OR 1.7 (95\% CI 1.1-2.9)] was obtained when we restricted the analysis to AML (190 cases) from the best coverage area (Lund-Helsingborg).

\section{Clonal chromosome aberrations}

Analyses by the presence of clonal chromosome abnormalities did not indicate that the increased overall risk associated with exposure to all organic solvents was predominantly associated with AML with an abnormal karyotype. In fact, the risk for AML with a normal karyotype in association with exposure to all organic solvents was somewhat higher than that for an abnormal karyotype (ta- 
Table 3. Categorical analysis of the intensity and duration of occupational and leisure-time exposure to all organic solvents as risk factors for acute myeloid leukemia. The analyses were restricted to cases and referents with exposure assessment with high confidence for the entire assessment period. ( $O R=$ odds ratio, $95 \% \mathrm{Cl}=95 \%$ confidence interval)

\begin{tabular}{|c|c|c|c|c|c|c|c|c|c|c|c|c|}
\hline \multirow{3}{*}{ Intensity } & \multirow{2}{*}{\multicolumn{4}{|c|}{ All }} & \multicolumn{8}{|c|}{ Age group } \\
\hline & & & & & \multicolumn{4}{|c|}{$20-60$ years $^{a}$} & \multicolumn{4}{|c|}{$\geq 61$ years $^{a}$} \\
\hline & Cases & Referents & OR & $95 \% \mathrm{Cl}$ & Cases & Referents & OR & $95 \% \mathrm{Cl}$ & Cases & Referents & OR & $95 \% \mathrm{Cl}$ \\
\hline \multicolumn{13}{|l|}{ Unexposed } \\
\hline 20 years' duration & 205 & 243 & 1.0 & & 94 & 103 & 1.0 & & 111 & 140 & 1.0 & \\
\hline $\begin{array}{l}\text { Hobby-low } \\
1-20 \text { years' duration }\end{array}$ & 70 & 57 & 1.5 & $1.0-2.3$ & 31 & 38 & 0.90 & $0.49-1.6$ & 39 & 19 & 2.7 & $1.4-4.9$ \\
\hline $1-7$ years' duration & 10 & 17 & 0.72 & $0.32-1.6$ & 4 & 12 & 0.36 & $0.11-1.2$ & 6 & 5 & 1.5 & $0.45-5.2$ \\
\hline $8-14$ years' duration & 18 & 15 & 1.5 & $0.73-3.1$ & 5 & 10 & 0.58 & $0.18-1.8$ & 13 & 5 & 3.3 & $1.1-9.6$ \\
\hline $15-20$ years' duration & 42 & 25 & 2.1 & $1.2-3.7$ & 22 & 16 & 1.5 & $0.70-3.3$ & 20 & 9 & 2.9 & $1.2-6.8$ \\
\hline \multicolumn{13}{|l|}{ Moderate } \\
\hline $1-20$ years' duration & 9 & 7 & 1.6 & $0.57-4.3$ & 3 & 5 & 0.66 & $0.15-2.8$ & 6 & 2 & 3.9 & $0.77-20$ \\
\hline \multicolumn{13}{|l|}{ High } \\
\hline $1-20$ years duration & 9 & 3 & 3.9 & $1.0-15$ & 6 & 2 & 3.5 & $0.69-18$ & 3 & 1 & .. & . \\
\hline Uncertain & 40 & 41 & 1.2 & $0.74-2.0$ & 19 & 20 & 1.1 & $0.52-2.1$ & 21 & 21 & 1.3 & $0.67-2.5$ \\
\hline
\end{tabular}

a The median duration of occupational exposure for the low-, moderate-, and high-intensity categories of the cases was 7, 5 and 9 years, respectively, for the 20 - to-60-year age group and 7,13 and 8 years, respectively, for the $\geq 61$-year age group.

Table 4. Effects of occupational and leisure-time exposure to all organic solvents with a duration of $\geq 1$ year, 20 years or earlier before the diagnosis on the risk for acute myeloid leukemia with regard to karyotype. Only the cases and referents with exposure assessment with high confidence were included in the analyses. (OR = odds ratio, $95 \% \mathrm{Cl}=95 \%$ confidence interval)

\begin{tabular}{|c|c|c|c|c|c|}
\hline Group & $\begin{array}{l}\text { Exposed } \\
\text { (N) }\end{array}$ & $\begin{array}{l}\text { Unexposed } \\
\text { (N) }\end{array}$ & $\begin{array}{l}\text { Uncertain } \\
\text { (N) }\end{array}$ & $\mathrm{OR}$ & $95 \% \mathrm{Cl}$ \\
\hline Referents & 67 & 243 & 41 & 1.0 & . \\
\hline \multicolumn{6}{|l|}{ Cases } \\
\hline Without karyotypic abnormality & 51 & 95 & 18 & 2.0 & $1.3-3.2$ \\
\hline With karyotypic abnormality & 37 & 110 & 22 & 1.4 & $0.83-2.2$ \\
\hline \multicolumn{6}{|l|}{ Number of abnormalities } \\
\hline One & 17 & 53 & 12 & 1.3 & $0.67-2.5$ \\
\hline Two & 6 & 20 & 3 & 1.3 & $0.44-3.6$ \\
\hline Complexa & 14 & 37 & 7 & 1.6 & $0.76-3.2$ \\
\hline \multicolumn{6}{|l|}{ Prognostic category } \\
\hline Good & 8 & 24 & 2 & 1.3 & $0.51-3.4$ \\
\hline Intermediate & 20 & 51 & 15 & 1.6 & $0.84-2.9$ \\
\hline Bad & 9 & 35 & 5 & 1.1 & $0.49-2.6$ \\
\hline \multicolumn{6}{|l|}{ Specific abnormality } \\
\hline$-3 / 3 p-$ & 1 & 8 & 1 & $\ddot{u}$ & \\
\hline$-5 / 5 q-$ & 8 & 28 & 4 & 1.2 & $0.59-2.5$ \\
\hline$-7 / 7 \mathrm{q}-$ & 5 & 23 & 1 & 1.0 & $0.35-2.9$ \\
\hline+8 (sole) & $7^{\mathrm{b}}$ & 4 & 2 & 11 & $2.7-42^{c}$ \\
\hline $\operatorname{der}(11)(q 23)$ & 0 & 4 & 0 &.. & \\
\hline$-12 / 12 p-$ & 5 & 16 & 1 & 1.0 & $0.34-3.1$ \\
\hline
\end{tabular}

a Refers to $\geq 3$ abnormalities.

b Two cases with only leisure-time exposure, 5 cases with occupational exposure ( 3 moderate, 2 high).

' Leisure-time exposure: $0 R 6.1,95 \% \mathrm{Cl} 1.7-22$; occupational exposure: $0 \mathrm{R}$ 9.6, $95 \% \mathrm{Cl} 2.21-44$; for subjects exposed to organic solvents, but not to benzene: OR $8.3,95 \% \mathrm{Cl} 1.8-38$.

ble 4). The risk was not differential with regard to the number of major abnormalities or prognostic category. Among the characteristic abnormalities, a high odds ratio was observed for trisomy 8 as the sole abnormality (OR 11, 95\% CI 2.7-42), whereas all other estimates were close to unity. Restriction to AML in the LundHelsingborg area gave a similar result (OR 19, 95\% CI $3.1-110$ ). The strong estimated effect for trisomy 8 was not due to benzene exposure alone. An increased risk was observed both for hobby exposure and occupational exposure. Out of 7 exposed cases with trisomy 8, 3 were ever-smokers. None had been treated with chemo- or radiotherapy.

\section{Morphological subtype}

We found no indications of a differential risk with regard to morphological subtype, with the exception of erythroleukemia, for which a higher risk from exposure to organic solvents was suggested (OR 4.2, 95\% CI 1.017, 5 exposed, 5 unexposed and 3 cases with uncertain exposure). None of the exposed cases had trisomy $8 ; 4$ 
were ever-smokers. None had been treated with radioor chemotherapy.

\section{Effect modification}

Although a weak effect from smoking was suggested (OR $1.3,95 \% \mathrm{CI} 0.96-1.8$, ever smokers versus nonsmokers), smoking did not modify the risk for AML from exposure to all organic solvents. Furthermore, no effect modification by gender was observed. In contrast, stratification by age indicated a higher risk at each intensity level of exposure to all organic solvents for cases diagnosed above the age of 60 years (table 3 ).

\section{Discussion}

The salient feature of the present study was the consistent association between exposure to organic solvents and risk for AML, especially in cases with trisomy 8 as the sole aberration. Contrary to our hypothesis, the associations were essentially nondifferential with regard to the overall presence of clonal chromosome abnormalities, as well as to total or partial losses of chromosomes 5 and 7. The hypothesis of an association between such exposure and trisomy 8 was less strong, having been based only on a few earlier publications $(10,31,33)$. In our study, 7 out of 13 with +8 as a sole anomaly had a history of exposure to organic solvents (table 4), a prevalence similar to that reported by Davico et al (33). It is, in this context, noteworthy that a review of treatment-related AML did not reveal a significantly higher incidence of trisomy 8 in such AML when compared with de novo AML (7). The possibility that exposure to organic solvents thus results in different karyotypic patterns than does exposure to radio- or chemotherapy is further supported by the present lack of an association between exposure to solvents and abnormalities of chromosomes 5 and 7, aberrations that are common in treatment-related AML (7). It remains to be seen whether other myeloid malignancies with trisomy 8 as a sole anomaly, especially myelodysplastic syndromes and chronic myeloproliferative disorders (1), are also associated with exposure to organic solvents.

The suggested higher risk for erythroleukemia than for other subtypes of $\mathrm{AML}$ in relation to exposure to all organic solvents is interesting, but it has previously only been reported in relation to a similar small number of cases from a pooled study (31) and a case-series of benzene-exposed workers $(50)$.

Our observations of consistently increased risks, even from low-level exposure (not exceeding $5 \%$ of the Swedish occupational exposure limits) to organic solvents are a source of worry. The results also indicate that exposure to organic solvents may contribute to an important proportion of the AML cases in the general population.
The most prevalent exposure was white spirit. For this agent, the observations would correspond to an effect level of $<15 \mathrm{mg} / \mathrm{m}^{3}$, which is remarkably low. In addition, an effect from leisure-time exposure only [OR 1.8, 95\% CI 0.92-3.5, not in results] was indicated.

Benzene exposure, which is an established risk factor for AML, did not fully explain the excess risk for exposure to organic solvents. The observed levels of benzene exposure were low ( $72 \%$ of the exposed cases were exposed to intensities below $0.07 \mathrm{ppm}$ ), and our modestly elevated OR estimates for benzene exposure are thus not in conflict with those of former studies.

We did not observe an increased risk in association with overall exposure to pesticides. The frequent use of proxy respondents for the cases did not permit a classification of the type of pesticide. Our findings of no increased risk with regard to the use of hair dyes are in accordance with the results of 2 former studies $(51,52)$, while 3 other studies (19-21) have been modestly supportive of such a risk. Previous studies of the risk for AML associated with exposure to. ELMF are conflicting and indicate a moderately increased risk, if any (26). Our results are compatible with this finding.

We may, to some extent, have underestimated the intensity and duration of exposure among the subjects by only using exposure assessments with high confidence. Bias resulting from such misclassification may be in either direction when more than 2 exposure categories are used in the analysis (53). However, for both the cases and referents classified as exposed to organic solvents, the average number of years assessed with high confidence was 18 (out of 20 possible); this finding indicates that this is a minor problem. In addition, we chose, on the basis of previous studies of treatment-related AML (12) and AML related to high benzene exposure (54), to focus exposure assessment on the 20 years before diagnosis. If less intense, and less toxic, exposure is associated with a longer latency time than 20 years, our assessments would underestimate relevant exposure durations.

An important aspect of the validity of the study is the differential use of proxy respondents for cases and referents; this use violates the comparable accuracy principle for the selection of referents (55) and may lead to negative information bias. However, when there is no indication of a substantial difference in information quality, the dominant use of proxy respondents for the cases and selfreports for referents is justified (56). The referents in our study reported the same median number of jobs held as the cases (table 1). In addition, no difference in the number of years assessed with high confidence was seen between the cases and referents for exposure to organic solvents. Thus no substantial difference in information quality was indicated, but the measures are crude. We refrained from adding respondent status as a covariate in the logistic regression model because such adjustments 
do not necessarily reduce the net bias (57). An effect estimate for organic solvents restricted to self-respondents did not indicate any substantial bias. Still, the clear difference in the proportion of next-of-kin interviews may have affected the effect estimates. This possibility especially applies to cases diagnosed for older people.

Although the assessment of exposure was made without knowledge of case-referent status, for ethical reasons, the nurses who carried out the interviews had this knowledge. This situation may have introduced a (positive) bias, but, in our opinion, it is likely to have been small since the interviews were rather firmly structured.

All referrals for cytogenetic investigations are made within the Swedish public health system, and there is therefore no reason to suspect any socioeconomically based selection bias among the cases, although cases diagnosed at older ages, when curative intended therapy is less frequent, are likely to be underrepresented. A lower participation rate among the referents than among the cases may, however, have introduced differential selection into the study with regard to, for example, socioeconomic factors, and therefore resulted in biased effect estimates. Such a selection would be likely to introduce a bias in the same direction for broad categories of exposure. We found no indications of such a general shift in the effect estimates for industrial-urban (gasoline and diesel fuel and exhaust gases and ELMF) or agricultural-rural (pesticides, fresh-meat-animal contact, fresh wood) exposures (table 2), but it cannot be ruled out.

The results of a reassessment of exposure to organic solvents agreed well with the results of the initial assessment. There were no differences in the agreement between the cases and referents.

The median duration of occupational exposure within dose categories was slightly higher for cases diagnosed at older ages ( $\geq 61$ years), and the proportion of next-ofkin interviews was higher than in the younger age group, but it is questionable whether or not this difference explains the suggested effect modification by age. One alternative interpretation is that AML induced by organic solvents occurs at an older age than AML with other etiologies. Another possibility is a stronger effect from exposure in that it has been suggested that the effect of a late-stage carcinogen would be more pronounced at an older age (58).

\section{Acknowledgments}

Per-Arne Hambert assisted with the exposure assessment. Siv Nilsson, Siv Hansson, and Ingegärd Nilsson performed the interviews. Gudrun Persson and Ulrika Wallin were responsible for the interview administration and data entry. Asta Persson and Gunnel Nilsson retrieved the medical records.

The project was supported by grants from the Swedish Council for Work Life Research, the Swedish Cancer Society, the Medical Faculty of Lund University, Lunds University Hospital, Gunnar, Arvid and Elisabeth Nilssons Research Foundation, and PREEM Research Foundation. The project was approved by the Ethics' Committee of Lund University.

\section{References}

1. Heim S, Mitelman F. Cancer cytogenetics. 2nd ed. New York (NY): Wiley-Liss, 1995.

2. Mitelman F, Mertens F, Johansson B. A breakpoint map of recurrent chromosomal rearrangements in human neoplasia. Nat Genet 1997;15:417-74.

3. Mitelman F. Chromosomal changes in cancer in relation to exposure to carcinogenic agents. In: Berlin A, Draper M, Hemminki K, Vainio H, editors. Monitoring human exposure to carcinogenic and mutagenic agents. Lyon: International Agency for Research on Cancer (IARC), 1984:351-60. IARC scientific publications, no 59.

4. Yamasaki H, Galiana C, Nakazawa H. Do genetic alterations found in tumors reflect exposure to carcinogens? In: Iversen $\mathrm{OH}$. New frontiers in cancer causation: exploring new frontiers. Washington (DC): Hemisphere Publishing Corporation 1993:153-66.

5. Li R, Yerganian G, Duesberg P, Kraemer A, Willer A, Rausch C, et al. Aneuploidy correlated 100\% with chemical transformation of Chinese hamster cells. Proc Natl Acad Sci USA 1997;94:14506-11.

6. Crane MM, Keating MJ, Trujillo JM, Labarthe DR, Frankowski RF. Environmental exposures in cytogenetically defined subsets of acute nonlymphocytic leukemia. JAMA 1989;262:634-9.

7. Johansson B, Mertens F, Heim S, Kristoffersson U, Mitelman F. Cytogenetics of secondary myelo-dysplasia (sMDS) and acute nonlymphocytic leukemia (sANLL). Eur J Haematol 1991:47:17-27.

8. Pedersen-Bjergaard $\mathbf{J}$, Rowley JD. The balanced and the unbalanced chromosome aberrations of acute myeloid leukemia may develop in different ways and may contribute differently to malignant transformation. Blood 1994;83:2780-6.

9. Johansson B, Billström R, Kristoffersson U, Åkerman M, Garwicz S, Ahlgren T, et al. Deletion of chromosome arm 3p in hematologic malignancies. Leukemia 1997;11:1207-13.

10. Smith MT, Zhang L, Wang Y, Hayes RB, Li G, Wiemels J, et al. Increased translocations and aneusomy in chromosomes 8 and 21 among workers exposed to benzene. Cancer Res 1998;58:2176-81.

11. Zhang L, Rothman N, Wang Y, Hayes RB, Li G, Dosemeci $M$, et al. Increased aneusomy and long arm deletion of chromosomes 5 and 7 in the lymphocytes of Chinese workers exposed to benzene. Carcinogenesis 1998;19:1955-61.

12. Linet MS, Cartwright RA. The leukemias. In: Schottenfeld D, Fraumeni J. Cancer epidemiology and prevention. 2nd ed. New York (NY): Oxford University Press, 1996:841—92.

13. Lynge E, Anttila A, Hemminki K. Organic solvents and cancer. Cancer Causes Control 1997;8:406-19. 
14. Flodin U, Fredriksson M, Axelson O, Persson B, Hardell L. Background radiation, electrical work, and some other exposures associated with acute myeloid leukemia in a case-referent study. Arch Environ Health 1986;41:77-84.

15. Törnqvist $S$, Knave B, Ahlbom A, Persson T. Incidence of leukaemia and brain tumours in some "electrical occupations". Br J Ind Med 1991;48:597-603

16. Richardson S, Zittoun R, Bastuji-Garin S, Lasserre V, Guihenneuc $\mathrm{C}$, Cadiou $\mathrm{M}$, et al, Occupational risk factors for acute leukemia: a case-control study. Int J Epidemiol 1992;21:1063-73.

17. Thériault G, Goldberg M, Miller AB, Armstrong B, Guenel P, Deadman J, et al. Cancer risks associated with occupational exposure to magnetic fields among electric utility workers in Ontarto and Quebec, Canada, and France: 1970-89. Am J Epidemiol 1994;15:550-72.

18. Feychting M, Forssén U, Floderus B. Occupational and residential magnetic field exposure and leukemia and central nervous system tumors. Epidemiology 1997;8:384-9.

19. Spinelli JJ, Gallagher RP, Band PR, Threlfall WJ. Multiple myeloma, leukemia, and cancer of the ovary in cosmetologists and hairdressers. Am J Ind Med 1984;6:97-102.

20. Teta MJ, Walrath J, Meigs JW, Flannery JT. Cancer incidence among cosmetologists. JNCI 1984;72:1051-7.

21. Mele A, Szklo M, Visani G, Stazi MA, Castelli G, Pasquini P, et al. Hair dye use and other risk factors for leukemia and preleukemia: a case-control study. Am J Epidemiol 1994 139:609-19.

22. Dich J, Zahm SH, Hanberg A, Adami HO. Pesticides and cancer. Cancer Causes Control 1997;8:420-43.

23. Lindquist R, Nilsson B, Eklund G, Gahrton G. Acute leukemia in professional drivers exposed to gasoline and diesel Eur J Heamatol 1991;47:98-103.

24. Metayer C, Johnson ES, Rice JC. Nested case-control study of tumors of the hematopoietic and lymphatic systems among workers in the meat industry. Am J Epidemiol $1998 ; 147: 727-38$

25. Jarvisalo J, Tola S, Korkala ML, Jarvinen E. A cancer register-based case study of occupations of patients with acute myeloid leukemia. Cancer 1984;54:785-90.

26. Portier CJ, Wolfe MS, editors. Assessment of health effects from exposure to power-line frequency electric and magnetic fields: working group report. Triangle Park (NC): National Institute of Environmental Health Sciences, 1998. NIH publication no, 98-3981.

27. Fourth International Workshop on Chromosomes in Leukemia (1982). The correlation of karyotype and occupationa exposure to potential mutagenic/carcinogenic agents in acute nonlymphocytic leukemia. Cancer Genet Cytogenet 1984;11:326-31.

28. Crane MM, Godwin JE, Annegers JF, Keating MJ. Is histological subtype a marker for environmental exposures in acute myelogenous leukemia. Cancer Epidemiol Biomarkers Prev 1992;1:183-8

29. Ciccone G, Mirabelli D, Levis A, Gavarotti P, Rege-Cambrin G, Davico L, et al. Myeloid leukemias and myelodysplastic syndromes: chemical exposure, histological subtype and cytogenetics in a case-control study. Cancer Genet Cytogenet $1993 ; 68: 135-9$

30. Pulsoni A, Stazi A, Cotichini R, Allione B, Cerri R, Di Bona $\mathrm{E}$, et al. Acute promyelocytic leukaemia: epidemiology and risk factors: a report of the GIMEMA Italian archive of adult leukaemia: GIMEMA Cooperative Group. Eur J Haematol $1998 ; 61: 327-32$.
31. Mitelman F, Nilsson PG, Brandt L, Alimena G, Gastaldi R, Dallapiccola B. Chromosomal pattern, occupation, and clinical features in patients with acute nonlymphocytic leukemia. Cancer Genet Cytogenet 1981;4:197-214.

32. Faglioli F, Cuneo A, Piva N, Carli MG, Previati R, Balbon $\mathrm{M}$, et al. Distinct cytogenetic and clinicopathologic features in acute myeloid leukemia after occupational exposure to pesticides and organic solvents. Cancer 1992;70:77-85.

33. Davico L, Sacerdote C, Ciccone G, Pegoraro L, Kerim S, Ponzio G, et al. Chromosome 8, occupational exposures, smoking, and acute nonlymphocytic leukemias: a populationbased study. Cancer Epidemiol Biomarkers Prev 1998; $7: 1123-5$.

34. Narod SA, Dubé ID. Occupational history and involvement of chromosomes 5 and 7 in acute nonlymphocytic leukemia. Cancer Genet Cytogenet 1989;38:261-9.

35. Rodella S, Ciccone G, Rege-Cambrin G, Vineis P, Working Group on the Epidemiology of Hematolymphopoietic Malignancies in Italy. Cytogenetics and occupational exposures in acute nonlymphocytic lenkemia and myelodysplastic syndrome [review]. Scand J Work Environ Health 1993;19:369 74.

36. Crane MM, Strom SS, Halabi S, Berman EL, Fueger JJ, Spitz $\mathrm{MR}$, et al. Correlation between selected environmental exposures and karyotype in acute myelocytic leukemia. Cancer Epidemiol Biomarkers Prev 1996;5:639— 44.

37. Sandler DP, Shore DL, Anderson JR, Davey FR, Arthur D, Mayer RJ, et al. Cigarette smoking and risk of acute leukemia: associations with morphology and cytogenetic abnormalities in bone marrow. JNCI 1993;85;1994-2003.

38. Mauritzson N, Johansson B, Albin M, Billström R, Ahlgren T, Mikoczy Z, et al. A single-center population-based consecutive series of 1500 cytogenetically investigated adult hematological malignancies: karyotypic features in relation to morphology, age and gender. Eur J Haematol 1999;62:95-102.

39. Bennett JM, Catovsky D, Daniel MT, Flandrin G, Galton DA, Gralnick HR, et al. Proposals for the classification of the acute leukaemias: French-American-British (FAB) co-operative group. Br J Haematol 1976;33:451—8.

40. Bennett JM, Catovsky D, Daniel M-T, Flandrin G, Galton DA, Gralnick HR, et al. Criteria for the diagnosis of acute leukemia of megakaryocyte lineage $(\mathrm{M} 7)$ : a report of the French-American-British cooperative Group. Ann Intern Med 1985;103:460-2.

41. Bennett JM, Catovsky D, Daniel MT, Flandrin G, Galton DA Gralnick HR, et al. A report of the French-American-British Cooperative Group: proposed revised criteria for the classification of acute myeloid leukemia. Ann Intern Med $1985 ; 103: 620-5$.

42. Bennett JM, Catovsky D, Daniel MT, Flandrin G, Galton DA, Gralnick HR, et al. Proposal for the recognition of minimally differentiated acute myeloid leukaemia (AML-M0). Br J Haematol 1991;78:325-9.

43. Mitelman F, Ed, ISCN: an international system for human cytogenetic nomenclature. Basel: Karger, 1995.

44. Floderus B, Persson T, Stenlund C. Magnetic-field exposures in the workplace: reference distribution and exposures in occupational groups. Int J Occup Environ Health 1996;2:22638.

45. Checkoway $\mathrm{H}$, Pearce NE, Crawford-Brown DJ. Research methods in occupational epidemiology. New York (NY): Oxford University Press, 1989.

46. Hosmer DW, Lemeshow S. Applied logistic regression. New York (NY): Wiley, 1989. 
47. Maclure M, Greenland S. Tests for trend and dose response: misinterpretations and alternatives. Am J Epidemiol 1992;135:96-104.

48. Greenland S. Variance estimators for attributable fraction estimates, consistent in both large strata and sparse data. Stat Med 1987;6:701-8.

49. Coughlin S, Benichou J, Weed D. Attributable risk estimation in case-control studies. Epidemiol Rev 1994;16:51—64.

50. Aksoy M. Malignancies due to occupational exposure to benzene. Am J Ind Med 1985;7:395-402.

51. Cantor K, Blair A, Everett G, VanLier S, Burmeister L, Dick $F$, et al. Hair dye use and risk of leukemia and lymphoma. Am J Public Health 1988;78:570-1.

52. Thun MJ, Altekruse SF, Namboodiri MM, Calle EE, Myers DG, Heath CW. Hair dye use and risk of fatal cancers in US women. JNCI 1994;86:210-5.

53. Rothman KJ, Greenland S. Modern epidemiology. 2nd ed. Philadelphia (PA): Lippincott-Raven, 1998.
54. Hayes RB, Yin SN, Dosemeci M, Li GL, Wacholder S, Travis LB, et al. Benzene and the dose-related incidence of hematologic neoplasms in China. JNCI 1997;89:1065-71.

55. Wacholder S, McLaughlin JK, Silverman DT, Mandel JS. Selection of controls in case-control studies, I: principles. Am J Epidemiol 1992;135:1019-28.

56. Wacholder S, Silverman DT, McLaughlin JK, Mandel JS. Selection of controls in case-control studies, II: types of controls. Am J Epidemiol 1992;135:1029-41.

57. Greenland S, Robins JM. Confounding and misclassification. Am J Epidemiol 1985;122:495-506.

58. Kaldor JM, Day NE. Mathematical models in cancer epidemiology. In: Schottenfeld D, Fraumeni J, editors. Cancer epidemiology and prevention. 2nd ed. New York (NY): Oxford University Press, 1996:127-37.

Received for publication: 24 November 1999 